\title{
Statistical analysis of long-term rainfall trends in Cherrapunji, Meghalaya, India
}

\author{
Surobhi Deka \\ Department of Statistics, Cotton University, Panbazar, Guwahati-781001 (Assam), India
}

Email: surobhi.deka@cottonuniversity.ac.in

\section{How to Cite}

Deka, S. (2021). Statistical analysis of long-term rainfall trends in Cherrapunji, Meghalaya, India. Journal of Applied and Natural Science, 13(1): 170 - 177. https://doi.org/10.31018/jans.v13i1.2442

\begin{abstract}
Rainfall is the key climatic variable that governs the regional hydrologic cycle and availability of water resources. Rainfall trend analysis in a localized watershed can improve many aspects of water resource management not only to the catchment itself but also to some of the related other catchments. The trend analysis of monthly rainfall data over Cherrapunji of Meghalaya in India for the period 1872-2007 has been carried out in this work. While the magnitude of the trend in the time series has been determined using Sen's estimator, the significance of the trend in monthly rainfall series has been tested using Mann-Kendall test. During the time span 1872-2007, an increasing trend has been found in the monthly rainfall for the months July, October and November, and a decreasing trend has been found in the monthly rainfall for the months February to June, August and September. On the other hand, it was found that none of Mann-Kendall $Z$ values was significant at $5 \%$ level of significance. Therefore, from Mann-Kendall $Z$ test, it can be concluded that there is no trend in any month in monthly rainfall for the station Cherrapunji. For the better assessment of the temporal variation in monthly rainfall trend, whole period was divided into two halves, $1872-$ 1939 and 1940-2007. Then, trend magnitude through Sen's estimator and Mann-Kendall Z for test of significance were determined for these two time periods separately. The analysis of trends of monthly rainfall in these two halves showed large variability in the magnitude and direction of the trend in various months from one half to another. Accurate prediction of trends in monthly rainfall is an important aspect of climate research and we believe that present study could provide a scope to correlate between current rainfall trend and climate change scenario of the study area.
\end{abstract}

Keywords: Cherrapunji, Mann-Kendall Test, Monthly Rainfall, Sen's Estimator, Trend Analysis

\section{INTRODUCTION}

Climate change, particularly that of the temperature and rainfall, is possibly one of the most significant universal environmental challenges being confronted by humanity today, with its significant impact on farming, natural ecosystems, human lives, assets and other weather related calamities. The main characteristics of climate change include rising temperatures, changes in rainfall pattern, melting of glaciers and sea ice, sea level rise and increased intensity and/or frequency of extreme events. Climate change analyses of extreme daily temperature and/or precipitation can be found in the literature. One such study was made by DeGaetano (1996) who did a study of the trend of extreme high and extreme low daily maximum and minimum temperatures over 22 stations in the northeastern United States. Caprio et al. (2009) used the iterative chi-square method in climate change analyses to include percent change in extreme daily weather events. For the details on the statistical procedure dealing with climate change, we refer to Hennemuth et al. (2013). Climate model analysis indicates that an increase in global surface temperature, as a consequence of the increase in greenhouse gases, with global warming can lead to an increase in the magnitude and incidence of extreme rainfall events (Trenberth et al., 2003, Letcher and Chazdon (2009)). Extreme precipitation events (heavy rainstorm, cloud burst) may have their own impacts in tropical areas which are reliant on farming and vulnerable to natural threats such as floods and droughts. Thus, in recent times in India, numerous authors have studied the pattern of extreme precipitation series for periods of different sizes, using data from several rain-gauge networks and a variety of approaches (Roy and Balling (2004), Goswami et al., 2006, Rajeevan et al., 2008, Guhathakurta et al., 2011). Earlier study over India (Roy and Balling (2004)) showed that most of the time series exhibited increasing 
trends in indices of precipitation extremes and that there were coherent regions with increases and decreases. Recent studies by Goswami et al. (2006), Rajeevan et al. (2008) and Guhathakurta et al. (2011) found that extreme rain events exhibited an increasing trend in the frequency and magnitude during monsoon season. For a more recent analysis of rainfall trends on a global scale, we refer to Caloiero (2017), Nyaupane (2018), Myhre et al. (2019), Papalexiou and Montanari (2019), Alashan (2020) and references therein.

A large number of studies relating to changing pattern of rainfall have been conducted for the Indian subcontinent (Mooley and Parthasarthy (1984), Thapliyal and Kulshrestha (1991), Lal (2001)). However altogether Indian yearly and monsoon precipitation during the past 100 years showed no significant trend, significant longterm rainfall variations were acknowledged at different spatial temporal scales in few studies (Dash et al., 2007, Dash and Hunt (2007), Kumar et al., 2010). Studies of precipitation data during the period 1871-2002 showed a declining trend in monsoon rainfall and increasing trend in the pre-monsoon and post-monsoon periods (Dash et al., 2007). During recent decades (1979-2006), the monsoon precipitation in Indian continent was declined by $4.5 \%$ compared to the period 1949-1978 (Ranade et al., 2008). Dash et al. (2009) concluded that short and dry spells were increasing while the long spells were decreasing as a whole. Several studies on Indian rainfall trend was carried out recently, and we refer to Bisht et al. (2018), Malik et al. (2019), Machiwal et al. (2019), Mallick et al. (2020), Panda and Sahu (2020).

The northeast region (NER) of India covers an area of 0.26 million $\mathrm{km}^{2}$. This land is one of the maximum rainfall-receiving provinces on the planet. Trends in monthly, seasonal, and annual rainfall and temperature on the subdivision and local scale for the NER were observed in Jain et al. (2013). Trend analysis of precipitation data series for the period 1871-2008 did not indicate any clear trend for the NER as a whole, though there are seasonal trends for some seasons over a few hydrometeorological stations. For the extreme rainfall occurrences in NER (Mahanta et al., 2013). Cherrapunji region on the Meghalaya plateau of northeastern India is considered to be one of the world's wettest place. The Meghalaya plateau is situated in the northeastern part of India and consists of high hills. The highest peak of the area is around $1,965 \mathrm{~m}$ above sea level. The average annual precipitation over the northeastern part of India, located at $80^{\circ} \mathrm{E}$ and $21^{\circ} \mathrm{N}$, varies between 2,000 to $4,000 \mathrm{~mm}$, with a maximum of $11,000 \mathrm{~mm}$ in Cherrapunji of Meghalaya, India. This amount of rainfall places it behind only nearby Mawsynram, Meghalaya, whose average is $11,873 \mathrm{~mm}$ and Mount Waialeale (USA) located on the Hawaiian island of Kauai, whose average is $11,684 \mathrm{~mm}$. Most of Cherrapunji's shower is the con- sequence of air being lifted as a large body of water vapour. Extremely large amounts of precipitation at Cherrapunji are conceivably the most well-known feature of orographic rain in the NER. As Cherrapunji is situated on the southern slope of the Meghalaya plateau, most of the rain flows directly down into Bangladesh. The amount of precipitation in the catchment area upstream of rivers is significant for the prediction of severe floods in Bangladesh. Murata et al. (2007) investigated the direct effect of the rainfall over Cherrapunji and the water level in adjoining rivers in Bangladesh. Monthly rainfall data from January 2003 to December 2003 were analyzed and concluded that water level in Bangladeshi rivers was significantly related to rainfall over Cherrapunji. Variation in the extreme rain events over the Meghalaya hills in the two halves of the twentieth century was studied by Prokop et al. (2015). A close-to-significant increase in the occurrence of extreme rainfall in Cherrapunji probably reveals a rise in the trend of cyclone incidence over the North Indian Ocean, including the Bay of Bengal, during the past few decades. For these reasons, it is imperative to understand the trends in precipitation over the Meghalaya state. However, the long-term rainfall trend in Meghalaya are not well explored. More recently, Marak et al. (2020) took up two important watersheds Umiam and Umtru in Meghalaya, and studied the spatial and temporal rainfall variations. The importance of trend analysis of rainfall over NER region can be found from the recent studies of Laskar et al. (2014), Das et al. (2015), Gharphalia et al. (2018), Yadav et al. (2016), Pradhan et al. (2019), Datta and Bose (2020). Although reasonable numbers of statistical analysis on seasonal rainfall data over different watersheds of Meghalaya districts have been proposed and studied in the literature, surprisingly, there has been considerably less work on the trend analysis of monthly rainfall data over Cherrapunji. In this study, the variation of monthly rainfall over Cherrapunji for the period of 1872 to 2007 was analyzed using Sen's estimator and Mann-Kendall method.

\section{MATERIALS AND METHODS}

\section{Data}

Series of monthly rainfall data over Cherrapunji (Fig 1) for the period of 1872 to 2007 was considered for this study. Monthly rainfall data (1872-2007) for the station Cherrapunjiare was obtained from the Regional Meteorological Centre, Guwahati. Compared to the number of total records, the number of missing data is much low. In literature, missing rainfall data are filled from the data of the nearest high correlating neighbouring stations. But in practice, it is very difficult to find a reference station with a high correlating and a homogeneous structure. In this study, missing data are filled using the fourth order accurate interpolation scheme from 


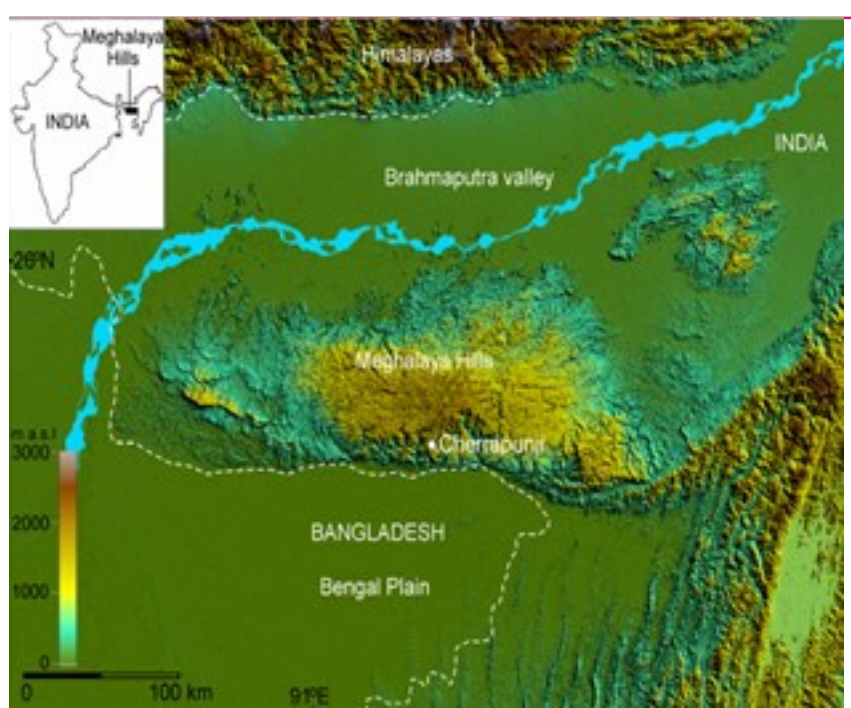

Fig. 1. Location map of the station Cherranjunji,Meghalaya Hills, India (Source: Prokop and Walanus (2015).

data of the nearest available data set. We suppose that data correction would have no significant influence on our analysis and conclusion.

\section{Methodology}

In this study, the magnitude of trend in a time series was determined using a nonparametric method known as Sen's estimator (Sen (1968)) and statistical significance of trend in the time series was analyzed using a non-parametric test known as Mann-Kendal (MK) test (Mann (1945), Kendall (1975)). Non-parametric tests are preferred over parametric tests because the problems aroused due to data skew can be evaded by nonparametric ones.

\section{Sen's Estimator}

Sen's method assumes a linear trend in the time series and has been widely used for determining the magnitude of the trend in hydro-meteorological time series (Lettenmaier et al. (1994), Yue and Hashino (2003), Partal and Kahya (2006)). In this method, the slopes $\left(T_{i}\right)$ of all data pairs are first calculated by

$$
T_{i}=\frac{x_{j}-x_{k}}{j-k} \text { for } i=1,2, \ldots \ldots . N
$$

(1)

Where $x_{j}$ and $x_{k}$ are data values at time $j$ and $k(j>k)$, respectively. The median of this $N$ of $T_{j}$ is Sen's estimator of the slope, which is calculated as follows

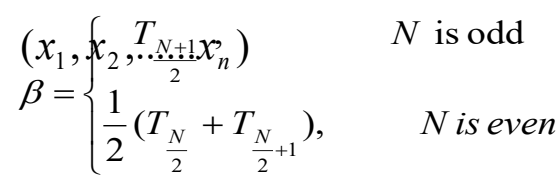

(2) Thus, in a two-sided test for trend, $\mathrm{H}_{0}$ should be accepted if $|Z| \leq Z^{\alpha} / 2$. A positive value of $S$ indicates an 'upward

A positive value of $\beta$ indicates an upward (increasing) trend and a negative value of $\beta$ indicates a downward (decreasing) trend in the time series.

\section{Mann-Kendall test}

Mann-Kendall test is the most commonly used test for trend analysis of any hydro-climatic series for checking spatial variation and temporal deviation. This formula was derived by both Mann and Kendall. Mann formulated it as a non-parametric test to detect trend whereas Kendall gave the test statistic distribution to test nonlinear trend and turning point. Mann described a nonparametric test for randomness against trend. The test is a particular application of Kendall's test for correlation commonly known as Kendall's Tau. According to Mann, the null hypothesis of randomness $\mathrm{H}_{0}$ states that the data are a sample of $n$ independent and identically distributed random variables. The alternative hypothesis $H_{1}$ of a two-sided test is that the distribution of $x_{k}$ and $x_{j}$ are not identical for all $k, j \leq n$ with $k \neq j$. The test statistic $S$ is defined as

$$
S=\sum_{k=1}^{n-1} \sum_{j=k+1}^{n} \operatorname{sgn}\left(x_{j}-x_{k}\right)
$$

where

$$
\operatorname{sgn}(\theta)=\left\{\begin{array}{l}
1, \text { if } \theta>0 \\
0, \text { if } \theta=0 \\
-1, \text { if } \theta<0
\end{array}\right.
$$

Mann shows that the distribution of $S$ is symmetrical and is normal in the limit as $n \rightarrow \infty$. Kendall gives the mean and variance of $S$ under $H_{\circ}$ given the possibility that there are ties in the values of $x$

$\mathrm{E}(\mathrm{S})=0$,

$$
\operatorname{Var}(S)=\left[n(n-1)(2 n+5)-\sum_{t} t_{i}(i)(i-1)(2 i+5)\right] / 18
$$

where $t_{i}$ is the extent of any given tie (number of $x$ 's involved in a given tie) and $\sum_{i}$ denotes the summation over all ties. For example (see, Hirsch et al. (1982)), if there were four ties of two and one tie of three, then

$$
\begin{aligned}
& \sum_{t} t_{i}(i)(i-1)(2 i+5) \\
= & 4(2 \times 1 \times 9)+1(3 \times 2 \times 11)=4 \times 18+1 \times 66=138
\end{aligned}
$$

Mann and Kendall derived the exact distribution of $S$ for $n \leq 10$ and shows that even for $n=10$ the normal approximation is excellent, provided one uses a continuity correlation of one unit. That is, one computes the standard normal variate $\mathrm{Z}$ by

$$
\mathrm{Z}= \begin{cases}(\mathrm{S}-1) / \sqrt{\operatorname{Var}(\mathrm{S})}, & \text { if } \mathrm{S}>0 \\ 0 & \text { if } \mathrm{S}=0 \\ (\mathrm{~S}+1) / \sqrt{\operatorname{Var}(\mathrm{S})}, & \text { if } \mathrm{S}<0\end{cases}
$$


trend' (increasing values with time) and a negative value of S indicates 'downward trend'.

If the time series data of interest are monthly rainfall data, then the null hypothesis Ho given above may be too restrictive. Examination of monthly rainfall time series suggests very strongly the presence of seasonality. Hirsch et al. (1982) proposed a test, the 'Seasonal Kendall test' for trend which is insensitive to the existence of seasonality. The null hypothesis $H_{o}^{\prime}$ for this is a relaxed form of $\mathrm{H}_{0}$ (which any seasonal but otherwise trend process will not violate). Let $\mathrm{X}=$ $\left(X_{1}, X_{2}, \ldots \ldots X_{12}\right)$ and $X_{i}=\left(x_{i 1}, x_{i 2}, \ldots x_{i n_{i}}\right)$. That is, $\mathrm{X}$ is the entire sample, made up of subsamples $X_{1}$ through $X_{12}$ (one of each month) and each subsample $X_{i}$ contains the $n_{i}$ annual values from month $i$. It is to be that there is no restriction that $n_{i}=n_{l}, i \neq l$ or that there be a value for every and month combination in the sampling period. However, there may be no more than one each year and month.

The null hypothesis $H_{o}^{\prime}$ for seasonal Kendall test is that $\mathrm{X}$ is a sample of independent random variables $\left(x_{i j}\right)$ and that $X_{i}$ is a subsample of independent and identically distributed random variables $\mathrm{i}=1,2, \cdots, 12$. We define the statistic $S_{i}$

$$
S_{i}=\sum_{k=1}^{n_{i}-1} \sum_{j=k+1}^{n_{i}} \operatorname{sgn}\left(x_{i j}-x_{i k}\right)
$$

Now, under $H_{o}^{\prime}$ the subsample $X_{i}$ satisfies the null hypothesis $H_{o}$ of Mann's test. Therefore, relying on Mann and Kendall we have

$$
E\left(S_{i}\right)=0 \text {, }
$$

$$
\operatorname{Var}\left(S_{i}\right)=\frac{n_{i}\left(n_{i}-1\right)\left(2 n_{i}+5\right)-\sum_{t_{i}} t_{i}(i)(i-1)(2 i+5)}{18}
$$

Distribution of $S_{i}$ is normal in the limit as $n_{i} \rightarrow \infty\left(t_{i}\right.$ is the extent of a given tie in the month $i$ ).

Following Hirsch et al. (1982), we define

$$
\mathrm{S}^{\prime}=\sum_{i=1}^{12} S_{i}
$$

and can derive its expectation, variance, and limit distribution.

$$
\begin{gathered}
E\left(S^{\prime}\right)=\sum_{i=1}^{12} E\left(S_{i}\right)=0 \\
\operatorname{Var}\left(S^{\prime}\right)=\sum_{i=1}^{12} \operatorname{Var}\left(S_{i}\right)+\sum_{i=1}^{12} \sum_{l=1}^{12} \operatorname{Cov}\left(S_{i} S_{l}\right)
\end{gathered}
$$

Here $S_{i}$ and $S_{l}(i \neq l)$ are functions of $X_{i}$ and $X_{l}$ respectively, $X_{i}$ are the data from the $i^{\text {th }}$ month and $X_{l}$ are the data from the $I^{\text {th }}$ month and $X_{i} \cap X_{l}=\phi$. Thus $S_{i}$ and $S_{l} \quad$ are also independent and hence $\operatorname{Cov}\left(S_{i} S_{l}\right)=0$. Further $S^{\prime}$ must be normal in the limit as $n_{i} \rightarrow \infty$, $i=1,2, \ldots .12$ being the sum of 12 distributions which are normal in the limit.

The exact distribution of $S^{\prime}$ is arrived at by enumerating all possible permutations and combinations of $S_{i}$ for the 12 months, summing the's, multiplying the independent probabilities, and adding the probabilities of all of the $S_{i} \quad$ sequences that sum to each particular value of $\mathrm{S}^{\prime}$. On the basis of visual inspection, Hirsch et al. (1982) have shown that even for records as short as 3 years the normal approximation works quite well for estimating $p=\operatorname{Pr} o b\left[\left|S^{\prime}\right| \geq s\right]$ and hence we assume that normal approximation will be a close agreement to detect the trend of long term monthly rainfall series. For the normal approximation, the standard normal variate $Z^{\prime}$ is defined as

$$
Z^{\prime}= \begin{cases}\left(S^{\prime}-1\right) / \sqrt{\operatorname{Var}\left(S^{\prime}\right)}, & \text { if } S^{\prime}>0 \\ 0, & \text { if } S^{\prime}=0 \\ \left(S^{\prime}+1\right) / \sqrt{\operatorname{Var}\left(S^{\prime}\right)}, & \text { if } S^{\prime}<0\end{cases}
$$

The conclusions are made accordingly.

\section{RESULTS AND DISCUSSION}

This section deals with results obtained from different statistical tools applied to analyze the monthly rainfall data for Cherrapunji region. The magnitude of the trend in the time series has been determined using Sen's estimator. The statistical significance of the trend in monthly series has been tested using the nonparametric Mann-Kendall (MK) test. Firstly, we analyze long-term (1872-2007) monthly rainfall trends. Then the monthly rainfall series for the time span 1872-2007 has been split into two equal halves, 1872-1939 and 1940-2007, in order to search for temporal variability. Further, to determine monotonic trend, modified MannKendall test, popularly known as seasonal Kendall test has been applied for all the three series separately.

In the first phase of this work, we calculated the month wise mean, standard deviation and coefficient of variation of the monthly rainfall data of Cherrapunji for three series of data. One series contains all monthly rainfall data during the period 1872-2007 and then the other two series are obtained by dividing these data into two equal halves, 1872-1939 and 1940-2007, as presented in Table 1. From the mean rainfall analysis, it was observed that Cherrapunji received maximum rainfall during the months from May to September. The variability in monthly rainfall data was high during the period 1940 -2007 as compared to the period 1872-1939 for all months except January, September, November and December.

In the next phase of the analysis, the magnitude of the trend in the monthly rainfall is determined using Sen's estimator and the statistical significance of the trend in monthly rainfall are analyzed using the value of $Z$ under the Mann-Kendall test. The values of $Z$ and Sen's estimator $\beta$ for different months during the period 1872-2007 are presented in Table 2. On observing 
Deka, S. / J. Appl. \& Nat. Sci. 13(1): 170 - 177 (2021)

the values of the Sen's estimator $\beta$ during the period 1872-2007, there was an increasing trend in the monthly rainfall for the months July, October and November, and a decreasing trend in the monthly rainfall for the months February, March, April, May, June, August and September. The values of $\beta$ for the months January and December were found to be zero which showed that there was no trend, increasing or decreasing, in these months. For the test of significance, the null hypothesis, as discussed in Section 2.2, is rejected at $5 \%$ level of significance if the calculated $|Z|>1.96$. But, it was found that none of Mann-Kendall $Z$ values was significant at $5 \%$ level of significance. Therefore, from Mann-Kendall $Z$ test it can be concluded that there was no trend in any month in monthly rainfall data for the station Cherrapunji. The values of $Z$ for the period 1872 -2007 are also shown in Fig.2, for the period 1872 to 1939 in Fig. 3 and for the period 1940 to 2007 in Fig. 4 for better illustration.

In order to search for temporal variability, monthly rainfall data for the time span 1872-2007 were split into two halves, 1872-1939 and 1940-2007. Trend magnitude through Sen's estimator and Mann-Kendall $Z$ for test of significance were determined for these two time peri- ods separately. The results are presented in Table 2 . As expected, the analysis of trends of monthly rainfall in these two halves showed large variability in the magnitude and direction of the trend in various months from one half to another. The values of Sen's estimator, for the months' May, June and October, depicted the decreasing trend during 1872-1939 and increasing trend during 1940-2007. On the other hand, for the months' March, April and July, an increasing trend during 18721939 and decreasing trend during 1940-2007 was observed. Almost no trend in both halves was found for the months November to February, August and September. However, none of the values of Mann-Kendall $Z$ was found to be significant in both periods.

Finally, to observe the monotonic trend in monthly rainfall data of Cherrapunji, we have applied the seasonal Kendall test, which eliminates the effect of seasonality, proposed by Hirch et al. (1982). The values of seasonal Kendall statistic $Z^{\prime}$ for the three series are presented in the last row of Table 2. From the values of $Z^{\prime}$, which was indifferent to the presence of seasonality, it was observed that there was no monotonic trend, increasing or decreasing, in the monthly rainfall data of Cherrapunjii.

Table 1. Mean and variation in Monthly rainfall data of Cherrapunji.

\begin{tabular}{|c|c|c|c|c|c|}
\hline Period (Year) & & Jan. & Feb. & Mar. & Apr. \\
\hline & Mean & 19.428919 & 48.495343 & 224.88637 & 725.99191 \\
\hline \multirow[t]{3}{*}{$1872-2007$} & S.D. & 28.904972 & 63.944352 & 227.0898 & 437.87666 \\
\hline & Coeff . of Var. & 149 & 132 & 101 & 60 \\
\hline & Mean & 19.788235 & 50.116176 & 227.63824 & 782.64412 \\
\hline \multirow[t]{3}{*}{$1872-1939$} & S.D. & 31.361163 & 44.87149 & 217.69309 & 443.89561 \\
\hline & Coeff . of Var. & 158 & 90 & 96 & 57 \\
\hline & Mean & 19.069603 & 46.87451 & 222.09343 & 669.33971 \\
\hline \multirow{2}{*}{$1940-2007$} & S.D. & 26.451471 & 78.867009 & 237.86181 & 427.52264 \\
\hline & Coeff . of Var. & 139 & 168 & 107 & 64 \\
\hline Period (Year) & & May & Jun. & Jul. & Aug. \\
\hline \multirow[t]{3}{*}{$1872-2007$} & Mean & 1269.225 & 2683.6676 & 2526.0654 & 1842.9868 \\
\hline & S.D. & 761.04314 & 1132.1911 & 1105.5462 & 839.83605 \\
\hline & Coeff. of Var. & 60 & 42 & 44 & 46 \\
\hline \multirow[t]{3}{*}{$1872-1939$} & Mean & 1240.0397 & 2645.8235 & 2441.5588 & 1871.025 \\
\hline & S.D. & 683.62802 & 962.99896 & 846.34735 & 690.80693 \\
\hline & Coeff. of Var. & 55 & 36 & 35 & 37 \\
\hline \multirow[t]{3}{*}{$1940-2007$} & Mean & 1298.4103 & 2721.5118 & 2610.5721 & 1814.9485 \\
\hline & S.D. & 835.42902 & 1285.5238 & 1316.0194 & 970.75561 \\
\hline & Coeff . of Var. & 64 & 47 & 50 & 53 \\
\hline Period (Year) & & Sep. & Oct. & Nov. & Dec. \\
\hline \multirow[t]{3}{*}{$1872-2007$} & Mean & 1115.1662 & 458.36397 & 58.038971 & 12.66912 \\
\hline & S.D. & 645.07281 & 427.69758 & 98.04353 & 31.96718 \\
\hline & Coeff. of Var. & 58 & 93 & 169 & 252 \\
\hline \multirow[t]{3}{*}{$1872-1939$} & Mean & 1165.7662 & 432.68382 & 52.405882 & 10.28971 \\
\hline & S.D. & 694.2693 & 379.07726 & 97.415949 & 32.03413 \\
\hline & Coeff . of Var. & 60 & 88 & 186 & 311 \\
\hline \multirow{3}{*}{$1940-2007$} & Mean & 1064.5662 & 484.04412 & 63.672059 & 15.04853 \\
\hline & S.D. & 592.65637 & 472.80279 & 99.06695 & 31.95897 \\
\hline & Coeff . of Var. & 56 & 98 & 156 & 212 \\
\hline
\end{tabular}




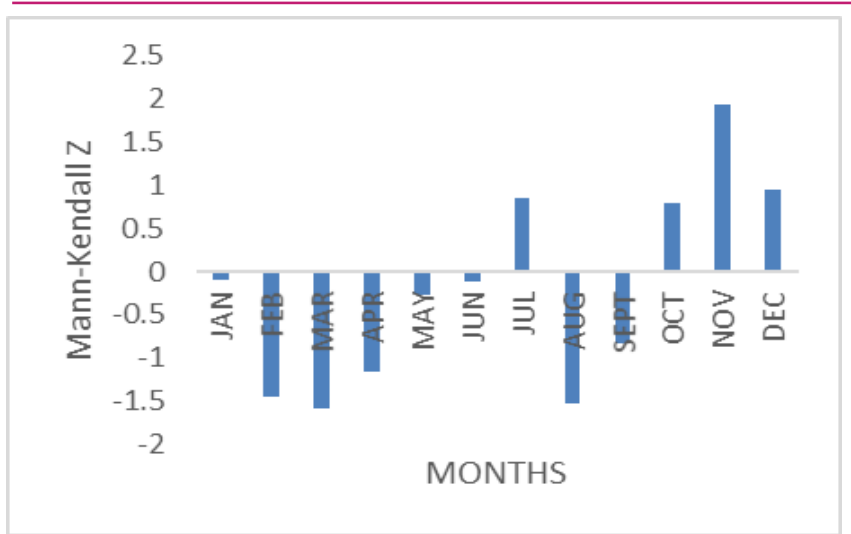

Fig. 2. Mann-Kendall Z for Monthly Rainfall Data of Cherrapunji for the Period 1872-2007.

Most tropical regions in the world are vulnerable to climate variability, given their dependence on rain-fed agricultural production and limited adaptive capacity owing to socio-economic conditions. In contrast to floods, all climatic zones irrespective of rainfall patterns can experience drought characterized by the reduction in the amount of precipitation received over an extended period of time which can range from a season, a year, to even a decade (Bond et al. 2008). The global increase in trends of floods and droughts have been linked to the changes in precipitation trends (Nyaupane et al. (2018), Papalexiou and Montanari (2019)). For these reasons, it is imperative to understand and identify the trends in precipitation for proper management and decision-making with regard to the efficient use of water resources. Despite the developments in studies concerning the climatology in other parts of the world, studies on a local scale are still very limited in the North East Region (NER) of India. For these reasons, it is imperative to understand and identify the trends in precipitation for proper management and decision-making with regard to the efficient use of water resources.

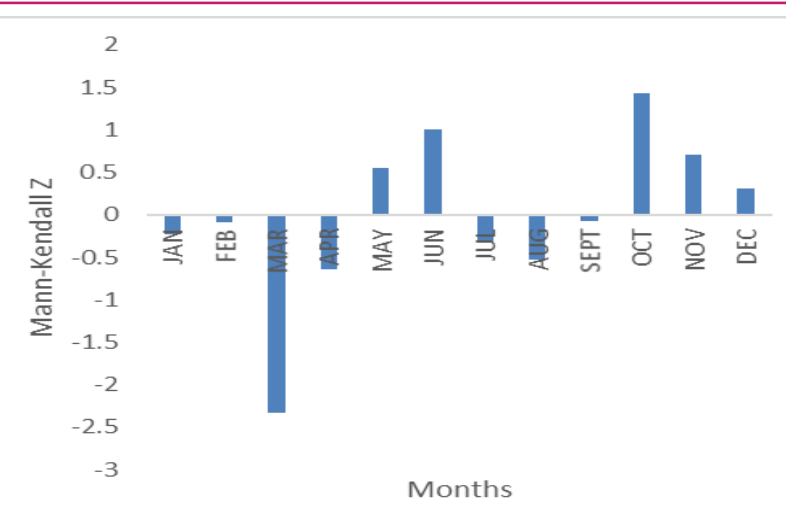

Fig. 3. Mann-Kendall Z for Monthly Rainfall Data of Cherrapunji for the Period 1872-1939.

Meghalaya is known to receive the most torrential rainfall in the world. Limitations are found in the available literature while analyzing trend analysis of rainfall over Meghalaya. However, here we briefly compare the findings of the article with those of available literature on rainfall analysis over the state Meghalaya. Choudhury et al. (2012) analyzed the rainfall data of a watershed Umiam in Meghalaya for the period 1983-2010. In their study, it was reported decreasing trend in monsoon rainfall, while non-significant increase in pre-monsoon and post-monsoon rainfall. Similar results were obtained in the study of Marak et al. (2020). Seasonal and annual rainfall variation in two important watersheds Umiam and Umtru in Meghalaya was analyzed using Innovative Trend Analysis (ITA) by Marak et al. (2020). Test results of Marak et al. (2020) for the gridded rainfall data from 1901 to 2018 showed that annual, winter, pre-monsoon, and monsoon rainfall is decreasing, whereas the post-monsoon rainfall is increasing. The decreasing trend in monsoon rainfall was also testified by Jain et al. (2013) for Assam and Meghalaya areas in their analysis for 1871-2008 period. These observa-

Table 2. Mann-Kendall Z and Sen's estimator of slope (mm/year) for monthly rainfall data of Cherrapunji.

\begin{tabular}{lllllll}
\hline \multirow{2}{*}{ Period Months } & \multicolumn{2}{c}{$\mathbf{1 8 7 2 - 2 0 0 7}$} & \multicolumn{2}{c}{$\mathbf{1 8 7 2 - 2 0 0 7}$} & \multicolumn{2}{c}{$\mathbf{1 9 4 0 - 2 0 0 7}$} \\
\cline { 2 - 7 } & $\begin{array}{l}\text { Mann- } \\
\text { Kendall Z }\end{array}$ & $\begin{array}{l}\text { Sen's } \\
\text { Estimator }\end{array}$ & $\begin{array}{l}\text { Mann- } \\
\text { Kendall Z }\end{array}$ & $\begin{array}{l}\text { Sen's } \\
\text { Estimator }\end{array}$ & $\begin{array}{l}\text { Mann- } \\
\text { Kendall Z }\end{array}$ & $\begin{array}{l}\text { Sen's } \\
\text { Estimator }\end{array}$ \\
\hline JAN & -0.0953 & 0 & -0.2269 & 0 & -0.4703 & -0.0120 \\
FEB & -1.4494 & -0.0900 & -0.089 & -0.0197 & -0.19 & 0 \\
MAR & -1.595 & -0.6069 & -2.3362 & -2.5000 & 0.2043 & 0.2355 \\
APR & -1.1671 & -1.0220 & -0.6363 & -1.6810 & 1.1069 & 2.4003 \\
MAY & -0.2643 & -4.479 & 0.5562 & 2.3571 & -1.715 & -9.6009 \\
JUN & -0.1241 & -0.2645 & 1.0057 & 6.1389 & -1.3492 & -9.8999 \\
JUL & 0.8614 & 1.9445 & -0.3159 & -1.6333 & 1.2875 & 9.1387 \\
AUG & -1.5357 & -2.6897 & -0.5295 & -2.2730 & -1.0024 & -4.8386 \\
SEPT & -0.8362 & -0.9672 & -0.0801 & -0.2452 & -1.2162 & -4.6116 \\
OCT & 0.7984 & 0.5388 & 1.4329 & 2.3808 & -0.2993 & -0.6667 \\
NOV & 1.9403 & .0339 & 0.712 & 0 & 0.6604 & 0.0488 \\
DEC & 0.9567 & 0 & 0.3026 & 0 & 1.4632 & 0 \\
Seasonal Kendall & -0.7262 & & -0.0604 & & -0.4402 & \\
\hline
\end{tabular}


tions were consistent with our findings for monthly rainfall data. The results of Marak et al. (2020) were also consistent with the findings in the study of Prokop and Walanus (2015).

\section{Conclusion}

In the present study, high variation in monthly rainfall data was observed during the period 1940-2007 for all months except January, September, November and December. For the study period 1872-2007, there was an increasing trend in the monthly rainfall for the months July, October and November, and a decreasing trend in the monthly rainfall for the months February, March, April, May, June, August and September. The monthly rainfall trend analysis for the two halves (18721939 and 1940-2007) showed large variability in the magnitude and direction of trend in various months from one half to another. On the other hand, MannKendall $Z$ values were found to be insignificant at $5 \%$ level of significance, which suggest that there was no trend in any month in monthly rainfall data for the station Cherrapunji. Finally applying the seasonal Kendall test, eradicating the influence of seasonality, it was observed that there was no monotonic trend in the monthly rainfall data of Cherrapunjii. Any cropproducing potentiality of an area depends primarily on the prevailing climate and soil conditions. A foreknowledge of rainfall pattern is of immense help not only to farmers but also to the authorities concerned with planning and management of water resources projects. The rainfall trend known for a particular station would help to predict the return value of rainfall event at a specific time in the future.

\section{ACKNOWLEDGEMENTS}

The author wishes to thank the anonymous referee for carefully reading the manuscript and his/her valuable comments, and suggestions that resulted in improving the overall presentation of the work.

\section{Conflict of interest}

The author declares that their is no conflict of interest.

\section{REFERENCES}

1. Alashan, S. (2020). Combination of modified MannKendall method and Sen innovative trend analysis, Engineering Reports, DOI: 10.1002/eng2.12131

2. Bisht, D. S., Chatterjee, C., Raghuwanshi, N. S. and Sridhar, V. (2018). Spatiotemporal trends of rainfall across Indian river basins, Theor. Appl. Climatol., 132, 419-436.

3. Bond, N. R., Lake, P. S. and Arthington, A. H. (2008). The impacts of drought on freshwater ecosystems: an Australian perspective, Hydrobiologia, 600, 3-16.
4. Caloiero, T., Coscarelli, R. and Ferrari, E. (2017). Analysis of rainfall trend in southern Italy through the application of the ITA technique, Eur. Water, 59, 199-206

5. Caprio, J. M., Quamme, H. A. and Redmond, K. (2009). A statistical procedure to determine recent climate change of extreme meteorological data as applied to two locations in the northwestern North America, Climate Change, 92, 65-81.

6. Choudhury, B. U., Das, A, Ngachan, S. V. et al. (2012). Trend analysis of long term weather variables in midaltitude Meghalaya, North-East India, J. Agric. Phys., 12, 12-22.

7. Das, S., Tomar, C. S., Saha, D., Shaw, S. O. and Singh, C. (2015). Trends in rainfall patterns over North-East India during 1961-2010, Int. J. Earth. Atmos. Sci., 2, 37-48.

8. Dash, S. K. and Hunt, J. C. R. (2007). Variability of climate change in India, Current Science, 93, 782-788.

9. Dash, S. K., Jenamani, R. K., Kalsi, S. R. and Panda, S. K. (2007). Some evidence of climate change in twentiethcentury India, Climate Change, 85, 299-321.

10. Dash, S. K., Kulkarni, M. A., Mohanty, U. C. and Prasad, K. (2009). Changes in the characteristics of rain events in India, J. Geophys Res., 114, 1-12.

11. Datta, $P$ and Bose, S. (2020). Assessing the changes in climate extremes over Karbi Anglong district of Assam, North-East India, Spat. Inf. Res., 28, 547-558.

12. DeGaetano, A. T. (1996). Recent trends in maximum and minimum temperature threshold exceedences in the northeastern United States, J. Climate, vol. 9, 1646-1657.

13. Gharphalia, B. J., Deka, R. L., Islam, A. N., Dutta, P. and Medhi, K.

14. (2018). Variability and Trends of Rainfall Events in the Brahmaputra Valley of Assam, India, Int. J. Curr. Microbiol. App. Sci., 7, 1902-1912.

15. Goswami, B. N., Venugopal, V., Sengupta, D., Madhusoodanan, M. S. and Xavier, P. K. (2006). Increasing trend of extreme rain events over India in a warming environment, Science, 314, 1442-1445.

16. Guhathakurta, P., Sreejith, O. P. and Menon, P. A. (2011). Impact of climate change on extreme rainfall events and flood risk in India, J Earth Syst Sc., 120, 359-373.

17. Hirsch, R., Slack, J. R. and Smith, R. A. (1982). Techniques of trend analysis for monthly water quality data, Water Resources Research, 18, 107-121.

18. Hennemuth, B., Bender, S., Bülow, K., Dreier, N., KeupThiel, E., Krüger, O., Mudersbach, C., Radermacher, C. and Schoetter, R. (2013). Statistical methods for the analysis of simulated and observed climate data, applied in projects and institutions dealing with climate change impact and adaptation, CSC Report 13, Climate Service Center, Germany.

19. Jain, S. K., Kumar, V. and Saharia, M. (2013). Analysis of rainfall and temperature trends in Northeast India, Int. J. Climatol, 33, 968-978.

20. Kumar, V., Jain, S. K. and Singh, Y. (2010). Analysis of long-term rainfall trends in India, Hydrological Sciences Journal, .55, 484-496.

21. Kendall, M. G. (1975). Rank correlation methods, $4^{\text {th }}$ ed., Charles Griffin, London.

22. Lal, M. (2001). Climatic change implications for India's water Resources, Journal of Indian Water Resource Society, 21, 101-119. 
23. Laskar, S. I., Kotal, S. D. and Bhowmik, S. K. R. (2014). Analysis of rainfall and temperature trends of selected stations over North East India during last century, Mausam, 65, 497-508.

24. Letcher, S. G. and Chazdon, R. L. (2009). Rapid recovery of biomass, Species Richness, and Species Composition in a Forest Chronosequence in Northeastern Costa Rica, Biotropica, 41, 608-617.

25. Lettenmaier, D. P., Wood, E. F. and Wallis, J. R. (1994). Hydro-climatological trends in the continental United States, 1948-88, Journal of Climate, 7, 586-607.

26. Machiwal, D., Gupta, A., Jha, M. K. and Kamble, T. (2019). Analysis of trend in temperature and rainfall time series of an Indian arid region: comparative evaluation of salient techniques, Theoretical and Applied Climatology, 136, 301-320.

27. Mahanta, R., Sarma, D. and Choudhury, A. (2013). Heavy rainfall occurrences in Northeast India, Int. J. Climatol., 33, 1456-1469.

28. Malik, A., Kumar, A., Guhathakurta, P. and Kisi, O. (2019). Spatial-temporal trend analysis of seasonal and annual rainfall (1966-2015) using innovative trend analysis method with significance test, Arabian Journal of Geosciences, 12, 1-23.

29. Mallick, J., Talukdar, S., Alsubih, M., Salam, R., Ahmed, M., Kahla, N. B. and Shamimuzzaman, M. (2020). Analyzing the trend of rainfall in Asir region of Saudi Arabia using the family of Mann-Kendall tests, innovative trend analysis, and detrended fluctuation analysis, Theoretical and Applied Climatology, doi.org/10.1007/s00704-020-03448-1.

30. Mann, H. B. (1945). Non-parametric tests against trend, Econometrica, 13, 245-259.

31. Marak, J. D. K., Sarma, A. K. and Bhattacharjya, R. K. (2020). Innovative trend analysis of spatial and temporal rainfall variations in Umiam and Umtru watersheds in Meghalaya, India, Theoretical and Applied Climatology, 142, 1397-1412.

32. Mooley, D. A. and Parthasarthy, B. (1984). Fluctuations of all India summer monsoon rainfall during 1871-1978, Climatic Change, 6, 287-301.

33. Murata, F., Hayashi, T., Matsumoto, J. and Asada, H. (2007). Rainfall in the Meghalaya plateau in Northeastern India-one of the rainiest places in the world, Nat Hazard, 42, 391-399.

34. Myhre, G., Alterskjær, K., Stjern, C. W., Hodnebrog, $\varnothing$., Marelle, L., Samset, B. H., Sillmann, J., Schaller, N., Fischer, E., Schulz, M. and Stohl, A. (2019). Frequency of extreme precipitation increases extensively with event rareness under global warming. Sci. Rep., 9, 110.

35. Nyaupane, N., Thakur, B., Kalra, A. and Ahmad, S. (2018). Evaluating future flood scenarios using CMIP5 climate projections, Water, 10, 1-18.

36. Panda, A and Sahu, N. (2020). Trend analysis of seasonal rainfall and temperature pattern in Kalahandi, Bolangir and Koraput districts of Odisha, India, Atmospheric Science Letters, DOI: 10.1002/asl.932.

37. Papalexiou, S. M. and Montanari, A. (2019). Global and regional increase of precipitation extremes under global warming. Water Resour. Res., 55, 4901-4914.

38. Partal, T. and Kahya, E. (2006). Trend analysis in Turkish precipitation data, Hydrological Processes, 20, 2011-2016.

39. Pradhan, R., Singh, N. and Singh, R. P. (2019). Onset of summer monsoon in Northeast India is preceded by enhanced transpiration. Sci. Rep. 9, 1-11.

40. Prokop, P. and Walanus, A. (2015). Variation in the orographic extreme rain events over the Meghalaya hills in Northeast India in the two halves of the twentieth century, Theor. Appl.Climatol., 121, 389-399.

41. Rajeevan, M., Bhate, J. and Jaswal, A. K. (2008). Analysis of variability and trends of extreme rainfall events over India using 104 years of gridded daily rainfall data, Geophys Res. Let.t, 35, L18707.

42. Ranade, A., Singh, N., Singh, H. N. and Sontakke, N. A. (2008). On variability of hydrological wet season, seasonal rainfall and rainwater potential of the river basins of India (1813-2006), Journal of Hydrological Research and Development, 23, 79-108.

43. Roy, S. and Balling, R. C. (2004). Trends in extreme daily precipitation indices in India, Int J Climatol, 24, 457-466.

44. Sen, P. K. (1968). Estimates of the regression coefficient based on Kendall's tau, J. Amer. Statist. Assoc., 63, 1379-1389.

45. Trenberth, K. E., Dai, A., Rasmussen, R. M. and Parsons D. B. (2003). The changing character of precipitation, Bull. Am. Meteorol. Soc., 84, 1205-1217.

46. Thapliyal, V. and Kulshrestha, S. M. (1991). Decadal changes and trends over India, Mausam, 42, 333-338.

47. Yadav, S., Deb, P., Kumar, S., Pandey, V. and Pandey, P. K. (2016). Trends in major and minor meteorological variables and their influence on reference evapotranspiration for mid Himalayan region at east Sikkim, India. J. Mt. Sci., 13, 302-315.

48. Yue, S. and Hashino, M. (2003). Long term trends of annual andmonthly precipitation in Japan, J. Am. Water. Resour., 39, 587-596. 